\title{
Design of Wedged Link Structure in Cabin Section Based on Contact Analysis
}

\author{
Long $\mathrm{Yi}^{1,}$, , Lei Chen ${ }^{1, b}$, Bowen Han ${ }^{1, \mathrm{c}}$, Yaoqin Zhang ${ }^{1, \mathrm{~d}}$, Liyuan Zhu ${ }^{1, \mathrm{e}}$ \\ ${ }^{1}$ Hongdu Aviation Industry Group, Nanchang 330024, China \\ aNWPUYL@163.com, b15667466@qq.com, ㄷnanhang_peng_yun@126.com, \\ d66060459@qq.com, enwpupy@163.com
}

\begin{abstract}
Keywords: Wedged Link; Contact Analysis; Parameter Design; Pre-stress.
Abstract. Wedged link is widely applied to circular cabin section linking structure for the advantages such as structure reliability, convenient installation and removal as well as high space utilization ratio. Generally, wedge block strength is computed using engineering method. However, the transfer load of wedge block must be obtain firstly, which is usually difficult. The adoption of finite element method makes it possible to simulate the complex load transferring path between wedge block and cabin body, thus obtaining a more comprehensive integral structural stress distribution. Nevertheless, the computation convergence is not satisfactory due to a number of contact surfaces. On the basis of ANSYS Parameter Design Language (APDL), the full contact analysis command stream of wedged link structure for typical circular cabin section is developed to carry out the detailed designs for structural size, tolerance fit clearance and pre-stress. A new structure form is obtained based on the contact analysis, which is more reliable for connecting and easy for manufacturing.
\end{abstract}

\section{Introduction}

Wedged link, thanks to its advantages such as small structural size, smooth appearance, high stiff-ness, reliable connection as well as convenient in-stallation and removal, is widely applied to the de-sign of medium and small diameter circular cabin section linking structures[1]. Generally, wedge block strength check takes the band connection check me-thod as reference, mainly including the check of permissible crushing stress and shear stress on working surface[2]. However, it is difficult to guaran-tee the precision of wedge block transfer load be-cause the load usually results from section load li-near computation. And it is also difficult to obtain the detailed stress distribution of cabin section structure. The adoption of finite element method[3,4] makes it possible to simulate the complex load transferring relationships between wedge block and wedge block, wedge block and cabin body, cabin body and cabin body, thus obtaining a more com-prehensive structural stress distribution. Neverthe-less, as there are numerous contact surfaces and the axial displacement of wedge block is mainly re-strained by friction force, it is likely to generate rigid-body displacement which will cause divergence in computation[5,6].

On the basis of ANSYS Parameter Design Language (APDL), the typical circular cabin section wedged link structure full contact finite element analysis command stream is developed[7-9]. With the adoption of parametric modeling for structural size, tolerance fit clearance and pre-stress, it completes the detailed structural designs. In accordance with the theoretical analysis and engineering application experience, the uprising wedge block, inverse wedge block and straight wedge block are compressed by pre-stress, the load is transferred through the surface and the strength margin is relatively large. Therefore, wedged link structure full contact finite element analysis model is established by taking the uprising wedge block, inverse wedge block and straight wedge block as an integral (collectively called wedge block), meanwhile it simulates the initial wedge block pre-stress through the thermal load, which enables it to build the contact relations between wedge block and the internal cabin body, wedge block and the external cabin body, as well as the internal cabin body and the external cabin body, so that to truthfully reflect the structural load trans-ferring status. The building of elastic connection structure between different independent wedge blocks and the adding of externally imposed dis-placement 
restraint on the elastic connection struc-ture effectively solve the problem of computation divergence which results from rigid-body displace-ment of wedge block. In the meantime, the impact of additional restraint on the mechanical structure can be reduced to the acceptable level for engineering by adjusting the elastic modulus parameter of elastic connection structure.

\section{Structural Scheme Design}

As can be seen from the dash area in Fig. 1, generally wedge blocks are evenly distributed in groups along the circular area of cabin section. The design of the quantity and distribution of wedge blocks can be optimized depending on the size and loading of cabin section.
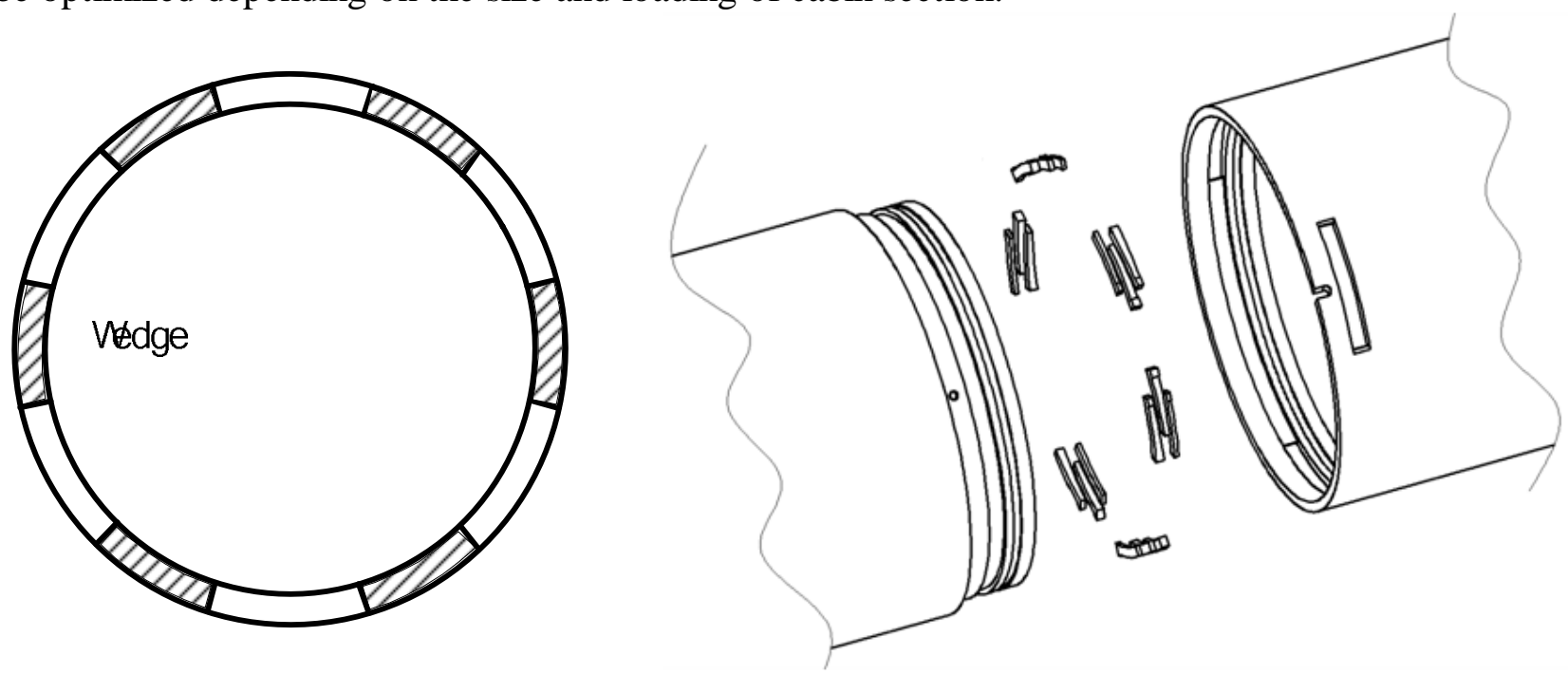

Fig. 1 Schematic Diagram of Wedge Block

Each group of wedge blocks is generally com-posed of the uprising wedge block, the inverse wedge block and the straight wedge block. For the installation, the straight and the inverse wedge blocks are set in the ring groove of cabin body first, then the uprising wedge block is pressed in between the straight and the inverse wedge blocks from right to left, which will be self-locked through friction force when pre-pressed. For the removal, as it is shown in Fig. 2, the uprising wedge block will be moved out of the ring groove when knocked from the opposite direction.

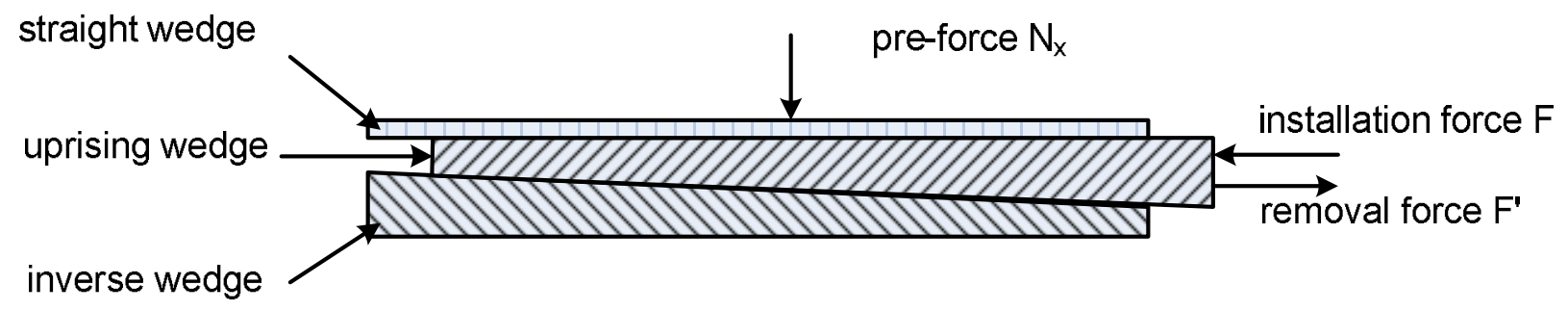

Fig. 2 Installation Diagram of Wedge Block

The force for the installation of uprising wedge block is shown as Eq. 1.

$$
F \leq \frac{\sin \theta+2 f \cos \theta-f^{2} \sin \theta}{\cos \theta-f \sin \theta} N_{x}
$$

In which, refers to the compressive pre-force in the $\mathrm{X}$ direction of wedge block, refers to the friction coefficient between the uprising wedge block and the straight and the inverse wedge blocks, and refers to the oblique angle of contact surface for the straight and the inverse wedge blocks. The removal force is shown as Eq. 2. 


$$
F^{\prime} \geq \frac{-\sin \theta+2 f \cos \theta+f^{2} \sin \theta}{\cos \theta+f \sin \theta} N_{x}
$$

In addition, when the condition $\theta<\operatorname{arctg}\left(\frac{2 f}{1-f^{2}}\right)$ is satisfied, the wedge block is equipped with self-locking function, i.e. it will not be fetched away between the straight and the inverse wedge blocks without the imposing of removal force.

As can be seen in Fig. 3, when the installation of wedge block is completed, the internal and the external cabin bodies make contact on compressive surface a to transfer axial compressive load; the wedge block and the external cabin body make contact on compressive surface $b$, and the wedge block and the internal cabin body make contact on compressive surface $\mathrm{c}$ to transfer axial tensile load.

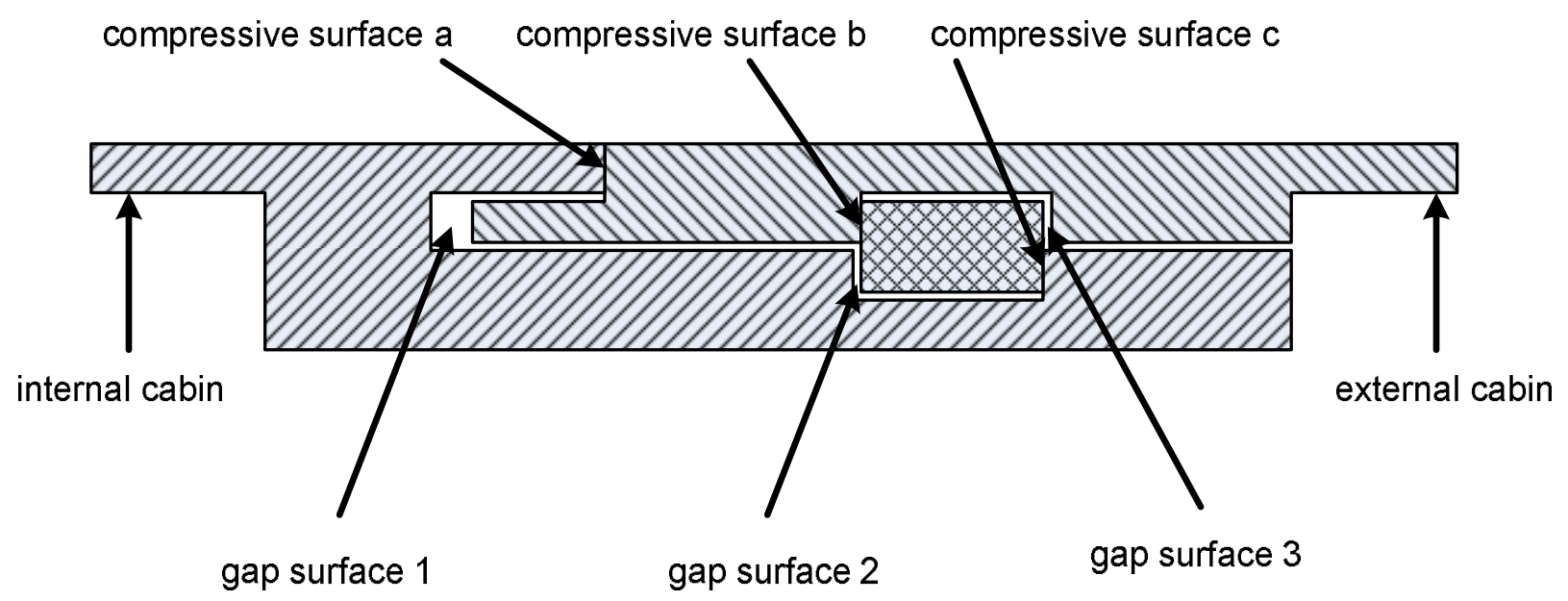

Fig. 3 Load Bearing Schematic Diagram of Wedge Block

For structural design, positioning is carried out with the use of surface a as reference. It should be ensured that the surface $a$ and $b$ and $c$ make contact, meanwhile the positions of 1,2 and 3 are all in gap state. Free tolerance can be adopted for the remain-ing parts, so the manufacture is easy and inexpen-sive.

\section{Contact Model}

The three-dimensional model of cabin section is built for the profile of wedged link structure presented in Figure 3. The clamped restraint is imposed on the right end and the typical internal force of section is imposed on the left end.

The 8-node solid element is adopted for mesh generation, and surface contact relations among the wedge block, internal cabin body and external cabin body are established. The wedge block and elastic connector are connected by sharing the nodes to impose the additional clamped restraint on elastic connector.

When the installation of the straight, uprising, inverse wedge blocks is completed, it constitutes the surface-compressed load bearing with relatively large strength margin. Therefore, it is viewed as an integral for modeling. For the wedge block, the internal and the external cabin bodies, the isotropic material model is adopted to define the elastic modulus and Poisson's ratio. For the coefficient of thermal expansion of wedge block, the anisotropic material model is applied. The actual value is used for the coefficient of thermal expansion in the X direction and the values at one order of magnitude lower is adopted in other directions for the convenient of simulating the pre-stress in the $\mathrm{X}$ direction of wedge block. The pre-stress of wedge block is imposed by temperature load, which is shown as Eq. 3 .

$$
\mathrm{T}=T_{0}+\frac{N_{x}}{\alpha_{x} S E}
$$


In which, $\mathrm{T}$ refers to the temperature load imposed on wedge block, ${ }^{T}{ }_{0}$ refers to the initial reference temperature, ${ }^{\alpha}$ refers to the coefficient of thermal expansion in the X direction of wedge block, $S$ refers to the area of vertical cross-section for wedge block and $\mathrm{X}$ axis, and $E$ refers to the elastic modulus of wedge block.

\section{Computation Result}

As can be seen in Fig.4, analysis is performed for elastic connecter with different elastic modulus and the additional clamped restraint bearing reaction of elastic connecter is extracted.

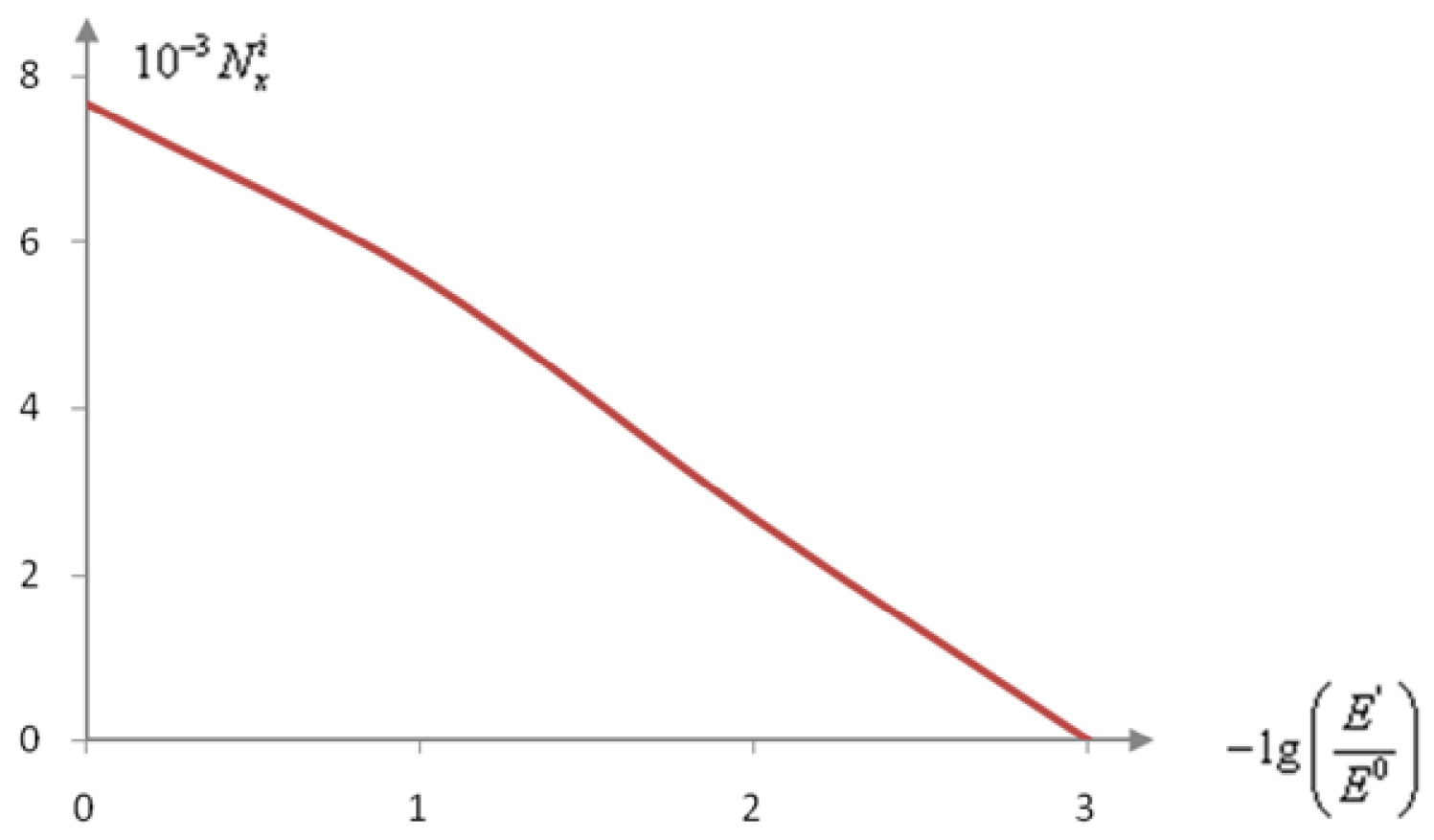

Fig.4 Relationship Between Reaction Force and Elastic Modulus of elastic connecter

In which $N_{x}^{i}$ stands for the bearing reaction of wedge block No. i in the X direction, $E^{\prime}$ stands for the elastic modulus of elastic connecter, $E^{0}$ stands for the elastic modulus of wedge block. It is demonstrated that when the elastic modulus of elastic connecter is three orders of magnitude lower than that of wedge block, the bearing reaction of elastic connecter is close to zero and the impact of additional clamped restraint of elastic connecter has little effect on structural force transfer, which meets the engineering requirement.

As shown in Table 1, the temperature load is imposed on wedge block and section force load is imposed on the structure in accordance with formula (3). The load direction is presented in Fig. 5. The transfer load of each wedge in the X direction is extracted as shown in Fig. 6.

Table 1 Section Load

\begin{tabular}{|c|c|}
\hline Fx & $-9000(\mathrm{~N})$ \\
\hline Fy & $-15000(\mathrm{~N})$ \\
\hline Fz & $-6000(\mathrm{~N})$ \\
\hline$M y$ & $2200(\mathrm{~N} \cdot \mathrm{m})$ \\
\hline $\mathrm{Mz}$ & $6200(\mathrm{~N} \cdot \mathrm{m})$ \\
\hline
\end{tabular}




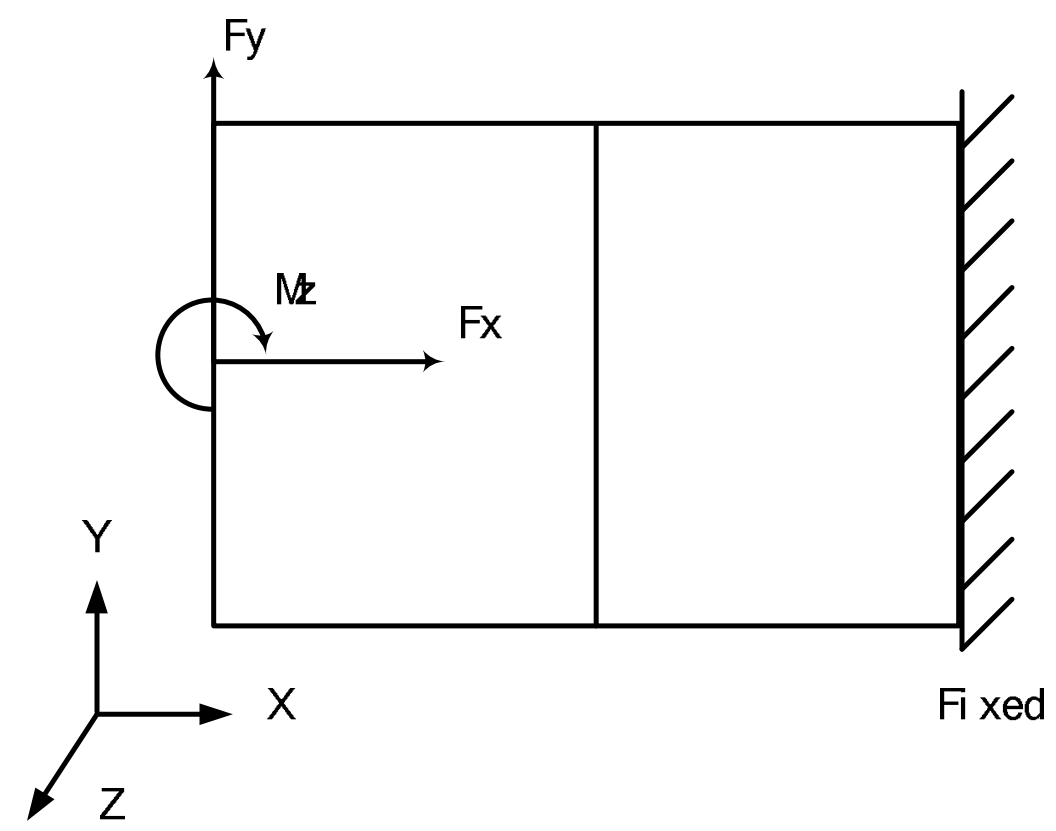

Fig.5 Schematic Diagram of the Loading

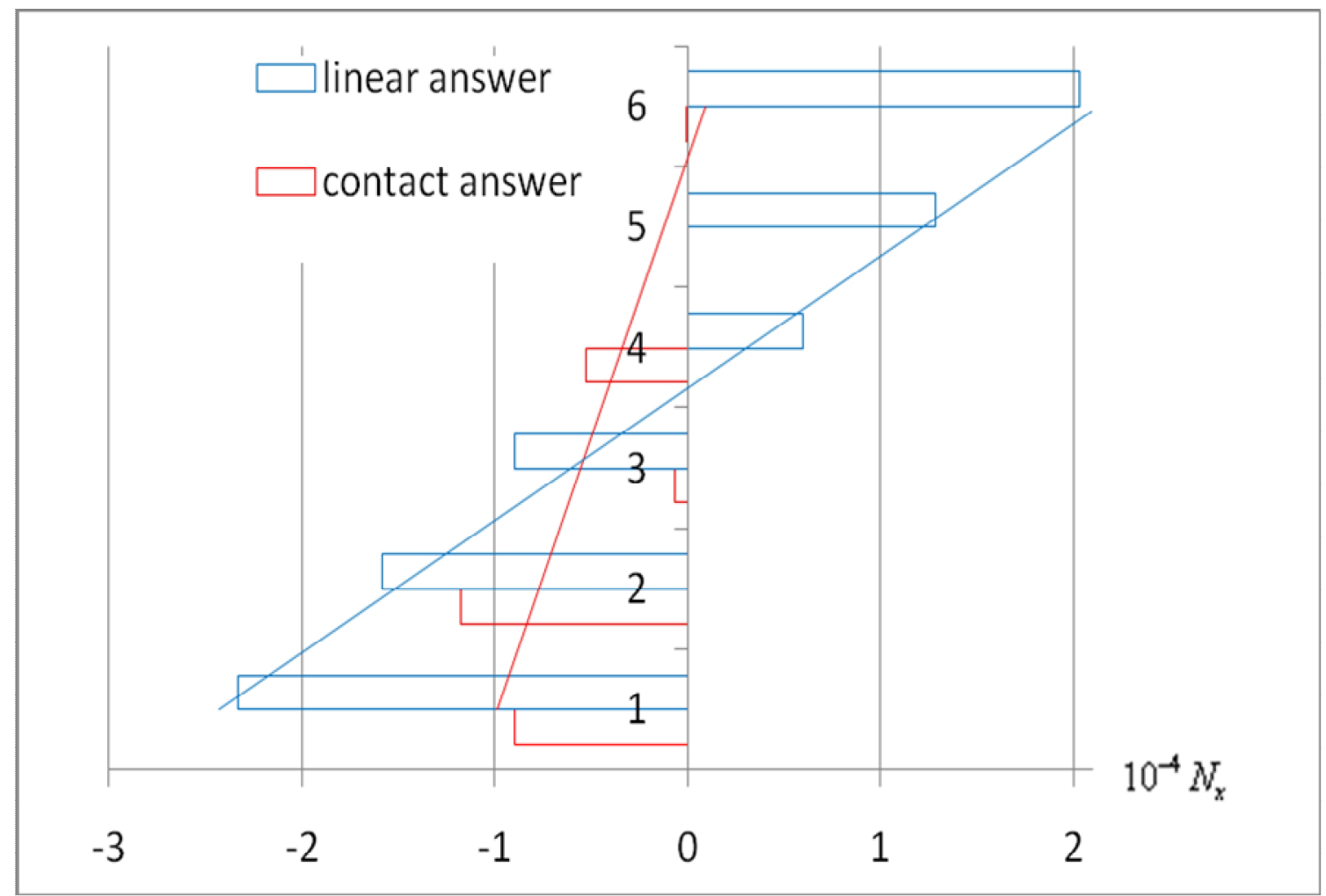

Fig.6 Computation Result of Wedge Block Transfer Force Load

As the cabin body is involved in load transfer on the compressive surface shown in Fig. 3, there is a big difference between wedge block transfer load analyzed with the application of contact model and that obtained by linear distribution computation, which conforms to the actual load transfer status in a better way. The result of finite element analysis is shown in Fig.7. 

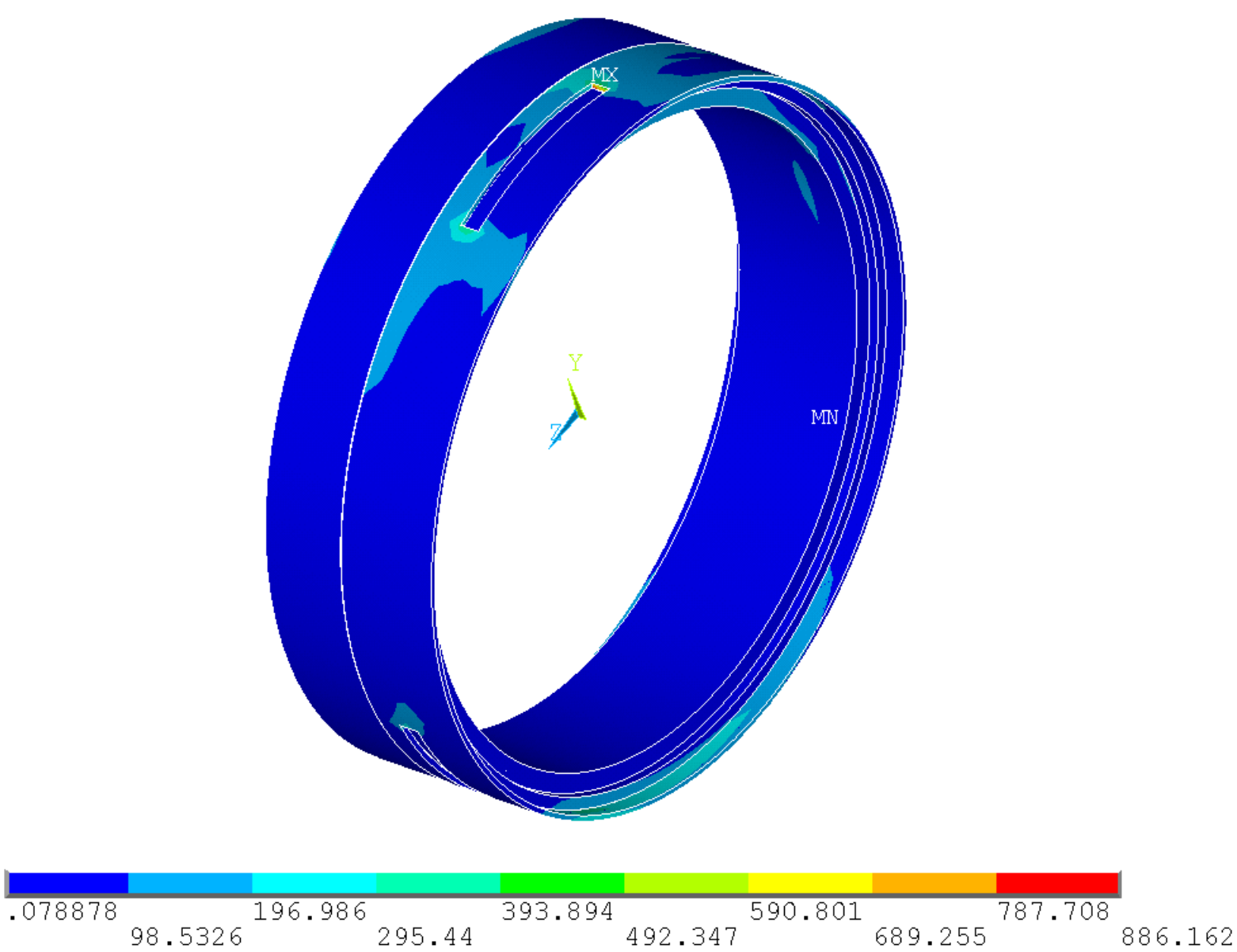

Fig.7 Equivalent Stress Nephogram of Internal Cabin Body

The result of analysis shows that the structural discontinuity of external cabin body is caused by the installation groove of wedge block, therefore, the stress level is relatively high, however, the stress concentration remains. The internal cabin body and wedge block have an even bear loading and the stress level is relatively low. As the elastic connecter is low in elastic modulus, its integral stress level is too low to take part in the integral load transfer.

\section{Conclusion}

1) On the basis of APDL, the full contact finite element analysis command stream of wedged link structure for typical circular cabin section is devel-oped to complete the detailed designs for structural size, tolerance fit clearance, pre-stress, etc., which significantly improves the efficiency of design;

2) It effectively simulates the initial pre-stress of wedge block in the $X$ direction through anisotropic material model for thermal expansion coefficient;

3) With the building of elastic connection structure between each independent wedge block and the adding of externally imposed displacement re-straint on the elastic connection structure, the prob-lem of computation divergence is solved effectively;

4) The result of analysis shows that the load transfer status of wedge block conforms to the de-sign objective and the analysis precision meets the engineering requirement, and the new structure form is obtained, which is more reliable for connecting and easy for manufacturing.

\section{References}

[1] Dj.M. Maric, P.F. Meier and S.K. Estreicher: Mater. Sci. Forum Vol. 83-87 (1992), p. 119 (In Chinese) 
[1] D.L. FAN, C.J. ZHANG, Y.B. SHEN: AVIATION MAINTENNCE \& ENGINEERING Vol. 1 (2012), p. 74-76 (In Chinese)

[2] X.Y. ZHENG, D. ZHANG, J.Q. JIANG: Mechanical Science and Technology for Aerospace Engineering Vol. 27(2008), p. 1665-1669 (In Chinese)

[3] X.C. YUAN: Internal Combustion Engine \& PowerPlant Vol. 31(2004), p. 10-13 (In Chinese)

[4] M. YUAN, C.G. QI, Z.H. ZHENG: Colliery Mechanical \& Electrical Technology Vol. 5(2008), p. $70-71$

[5] L.F. WU, X.C. YIN, K. WU: Journal of Mechanical Strength Vol 30(2008), p. 405-410 (In Chinese)

[6] A.H. LIAO, H.W. ZHANG, C.H. WU: Journal of Mechanical Strength Vol. 28(2006), p. 282-286 (In Chinese)

[7] P. HUANG, J. MO, B. XU: Journal of Mechanical Strength Vol. 27(2005), p. 191-195 (In Chinese)

[8] R.G. Zhao, Z.F. Chen, Y.J. Xu, S.Q. Hu: JOURNAL OF VIBRATION ENGINEERING Vol. 17(2004), p. 820-824 (In Chinese)

[9] P. HUANG, Y.H. YIN, J. MO: CHINESE JOURNAL OF MECHANICAL ENGINEERING Vol. 42(2006), p. 205-209 (In Chinese) 